\title{
Exploring the potentials of selected bioactive compounds isolated from Piper guineense Schumach. \& Thonn. leaf toward identification of novel pfDHFR and pfDHODH inhibitors as antimalaria agents
}

\author{
Oluwafemi Adeleke Ojo* \\ Phytomedicine, Natural Products, Drug and Biochemical Toxicology Group, Department of Biochemistry, Landmark University, Omu Aran, Nigeria.
}

\begin{tabular}{|c|c|}
\hline ARTICLE INFO & ABSTRACT \\
\hline $\begin{array}{l}\text { Received on: } 10 / 08 / 2020 \\
\text { Accepted on: } 28 / 10 / 2020 \\
\text { Available online: } 05 / 04 / 2021\end{array}$ & $\begin{array}{l}\text { Present antimalarial drugs have been related to several adverse side effects, including headache, depression, nausea, } \\
\text { and itchy skin. Thus, exploring bioactive compounds from a natural origin, which possess drug-like properties with } \\
\text { no side effects, is of great importance. This study was designed to assess the molecular relations obtainable between } \\
\text { piperine, pipercide, and piperlongumine compounds isolated from Piper guineense Schumach. \& Thonn. leaf and }\end{array}$ \\
\hline $\begin{array}{l}\text { Key words: } \\
\text { Piper guineense, molecular } \\
\text { docking, pfDHFR, } \\
\text { pfDHODH, rule of five, } \\
\text { toxicity. }\end{array}$ & $\begin{array}{l}\text { targeted receptor linked to malaria Plasmodium falciparum dihydrofolate reductase (pfDHFR) and Plasmodium } \\
\text { falciparum dihydroorotate dehydrogenase (pfDHODH) for antimalarial properties. The result showed that piperine } \\
(-8.3 \mathrm{kcal} / \mathrm{mol}) \text { from } P \text {. guineense binds to } \mathrm{pfDHFR} \text { with high affinity and low free energy than the other compounds } \\
\text { and standard ligand pyrimethamine }(-7.8 \mathrm{kcal} / \mathrm{mol}) \text {. In contrast, pyrimethamine }(-8.4 \mathrm{kcal} / \mathrm{mol}) \text { and pipercide }(-8.3 \\
\mathrm{kcal} / \mathrm{mol}) \text { show a better binding affinity to pfDHODH. Hence, the results provided insights into the development of } \\
\text { better piperine and pipercide as a replacement to present antimalarial agents, with further analysis worth considering. }\end{array}$ \\
\hline
\end{tabular}

\section{INTRODUCTION}

Malaria is endemic in over 100 nations as it is caused by Plasmodium parasites. Plasmodium falciparum is communicated solely via the bites of female Anopheles mosquito. If not managed well within 24 hours of infection, it can lead to austere sickness, resulting in death. The prevalence of malaria has been the main cause of death in adults and infants worldwide. Recent estimates show that about 228 million cases occurred worldwide in 2018 with the increasingly prominent in regions like Africa and Asia (World Health Organization, 2019). In Nigeria, malaria is the leading cause of death in both infants and adults as Nigeria accounts for $25 \%$ of the malaria cases worldwide (World Health

"Corresponding Author

Oluwafemi Adeleke Ojo, Drug and Biochemical Toxicology Group, Department of Biochemistry, Landmark University, Omu Aran, Nigeria. E-mail: oluwafemiadeleke08@gmail.com
Organization, 2019). Hence, it is of great importance to developing natural compounds with improved effectiveness to fight malaria.

Countless antimalarial drugs have been technologically advanced which include quinolones, pyrimethamine, chloroquine, and artemether but with numerous side effects (Singh and Mishra, 2018). Antifolates have been generally employed as an effective antimalarial molecule with their efficacy being slowed down by a fast increase of resistance at the active site of dihydrofolate reductase (David et al., 2018). Inhibitors of antifolates target, one of the key pathways for the existence of a malaria parasite, are referred to as folate metabolism (Singh and Mishra, 2018). One of the major enzymes inhibited in folate metabolism is dihydrofolate reductase (DHFR)-thymidine synthase. DHFR is an enzyme that performs a secondary role, but an important role, in DNA synthesis and other several processes. It controls the level of folate, responsible for the transportation of carbon atoms to enzymes that requires them; for example, thymidylate synthase builds thymine bases in DNA formation via the carbon atoms. Pyrimethamine inhibits DHFR, an enzyme critically implicated in the de novo folate biosynthesis, required for the biosynthesis of purines and 
pyrimidines (David et al., 2018; Singh and Mishra, 2018). Thus, its inhibition hinders the synthesis of key metabolites needed for the production of nucleotides and proteins. Furthermore, nucleic acid bases are vital for RNA and DNA synthesis (Loffler et al., 2005). The cellular access to pyrimidine bases in humans is through the de novo synthesis and salvage pathway. Inhibition of de novo synthesis implies the dependence on the salvage pathway to sustain the cell. Nevertheless, Plasmodium species come up short on the salvage pathway of pyrimidine; thus, the de novo synthesis inhibition leads to cellular death, rendering the parasites powerless against the hindrance of dihydroorotate dehydrogenase (DHODH) (Phillips and Rathod, 2010). This de novo biosynthesis of the pyrimidine pathway plays an essential role in parasite as it lacks the salvage pathway. DHODH is a catalyst that catalyzes the FMN-dependent redox response in the de novo biosynthesis pathway of pyrimidine and is an all-around portrayed objective for the revelation of antimalarial drugs (Vyas and Ghate, 2011).

Numerous side effects have been documented to be linked to the usage of $P$. falciparum dihydrofolate reductase (pfDHFR) and $P$. falciparum dihydroorotate dehydrogenase (pfDHODH) like pyrimethamine which causes a headache, vomiting, itchy skin, and allergic reactions. Thus, it is important to develop novel antimalarial drugs with high effectiveness and fewer side effects as a result of documented mortality and the spread of malaria with the use of preexisting medications and their side effects. Piper guineense Schumach. \& Thonn. has been documented to contain several bioactive compounds such as piperine, pipercide, and piperlongumine (Adebayo et al., 2003; Oyinloye et al., 2017). Hence, this study predicts the drug-like properties and molecular docking of some compounds as inhibitors of pfDHFR and pfDHODH in managing malaria.

\section{MATERIALS AND METHODS}

\section{Receptor protein}

The three-dimensional structure (3D) of pfDHFR (PDB ID: 3QG2) and pfDHODH (PDB ID: 1TV5) was recovered from the protein data bank repository (www.rcsb.org).

\section{Bioactive compounds retrieval}

The three bioactive compounds docked were isolated from P. guineense by Adebayo et al. (2003). The database used in retrieving the chemical structure of the four compounds (piperine, pipercide, piperlongumine, and pyrimethamine) was PubChem (https://pubchem.ncbi.nlm.nih.gov/) in the format of structuredata file (SDF). The database contains a large number of chemical compounds that have been validated and gives vital details that unravel substances obtained from PubChem (Oyinloye et al., 2019). Chimera was employed in the conversion of SDF files to PDB format.

\section{Preparation of protein}

Protein preparation (pfDHFR and pfDHODH) using molecular docking involved the removal of nonpolar hydrogens, small molecules, lone pairs, cocrystallized water molecules, and nonstandard residues and merging and addition of hydrogens and Gasteiger charges. Dock Prep was used for geometry optimization and energy minimization (for the 1,000 steepest descent steps) of pfDHFR and pfDHODH before docking using University of California at San Francisco Chimera (Resource for Biocomputing, Visualization, and Informatics, San Francisco, CA). The prepared receptor was saved as a .pdb file and utilized for molecular studies.

\section{Ligand preparation}

The 3D ligand structures were retrieved in SDF format from PubChem and then converted to PDB format using chimera. The structures were energy-minimized for the 1,000 steepest descent steps, hydrogens and Gasteiger charges were added and merged and then saved as a .pdb file.

\section{Docking studies}

To simulate binding affinity between the receptor protein and bioactive compounds, the docking tool, AutoDock Vina (version 1.1.2), was used (Ojo et al., 2019). Piperine, pipercide, piperlongumine, and pyrimethamine were firstly docked into the target protein active sites using AutoDock Vina. The protocol was employed taking into consideration the ligand flexibleness in a manner that set all rotational bonds free and also the appropriate binding energies for the best pose were noted (Ojo et al., 2020b). Using the AutoDock tool, the compounds had the addition of Gasteiger charges and a maximum of six numbers of active torsions were set. The spacing parameters of grid points were adjusted to cover the entire active site residues of pfDHFR and pfDHODH and the default value $0.375 \AA$ was set between grid points.

\section{Predictions of Absorption, Distribution, Metabolism, Excretion, and Toxicity (ADMET)}

ADMET analysis was employed to ascertain the pharmacological attributes of the four compounds. For this study, AdmetSAR (predated.bmdrc.kr) and SwissADME (http://www. swissadme.ch) servers were utilized to speculate and outline vital drug-likeness like harmful dosage level, mutagenicity, and pharmacokinetically pertinent attributes of all the bioactive compounds (Ojo et al., 2019).

\section{RESULTS AND DISCUSSION}

All three compounds revealed a good binding affinity with pfDHFR and pfDHODH. Piperine having the best docking score of $-8.3 \mathrm{kcal} / \mathrm{mol}$ for pfDHFR than other compounds and standard drug pyrimethamine. Docking scores of all four compounds were listed in Table 1. In contrast, pyrimethamine and pipercide revealed a better binding affinity for pfDHODH than other compounds with -8.4 and $-8.3 \mathrm{kcal} / \mathrm{mol}$, respectively. The top interaction poses for the piperine, pipercide, piperlongumine, and pyrimethamine having higher binding interaction were spotted having a deep association with the binding site of pfDHFR and

Table 1. Binding energy in $\mathrm{Kcal} / \mathrm{mol}$ of piperine, pipercide, piperlongumine, and pyrimethamine with pfDHFR and pfDHODH

\begin{tabular}{lcc}
\hline Compounds & $\begin{array}{c}\text { pfDHFR docking score } \\
\text { (Kcal/mol) }\end{array}$ & $\begin{array}{c}\text { pfDHODH docking score } \\
\text { (Kcal/mol) }\end{array}$ \\
\hline Piperine & -8.3 & -7.0 \\
Pipercide & -7.5 & -8.3 \\
Piperlongumine & -7.7 & -5.9 \\
Pyrimethamine & -7.8 & -8.4 \\
\hline
\end{tabular}


pfDHODH showing all the most vital interactions. The bonded and nonbonded associations of these compounds are also revealed. Piperine interaction with pfDHFR residues revealed that the side chains of ASN521 AND HIS491 formed hydrogen bonds with the ligand. Besides, the interaction of pipercide with pfDHFR showed that the side chains of ARG122, VAL45, and GLY44 formed hydrogen bonds with the ligand. Also, the interaction of piperlongumine with pfDHFR revealed that the side chain ASN108 formed a hydrogen bond with the ligand, while the interaction of pyrimethamine with pfDHFR showed that LEU164, CYS15, and ASP54 formed hydrogen bonds with the ligand (Fig. 1). Furthermore, Figure 1 shows that piperine and pyrimethamine form a pi-pi stacking using its phenyl ring with PHE520 and PHE58, respectively, which could enhance the compound potency.

Molecular docking tools were used to assess the pfDHFR inhibitory potentials of piperine, pipercide, and piperlongumine using pyrimethamine as the standard ligand. The amino acid residue of human DHFR differs from that of pfDHFR by the substitution of residues PHE31, GLN35, and ASN64 with MET55, CYS/ARG59, and PHE116 in pfDHFR (Yuthavong
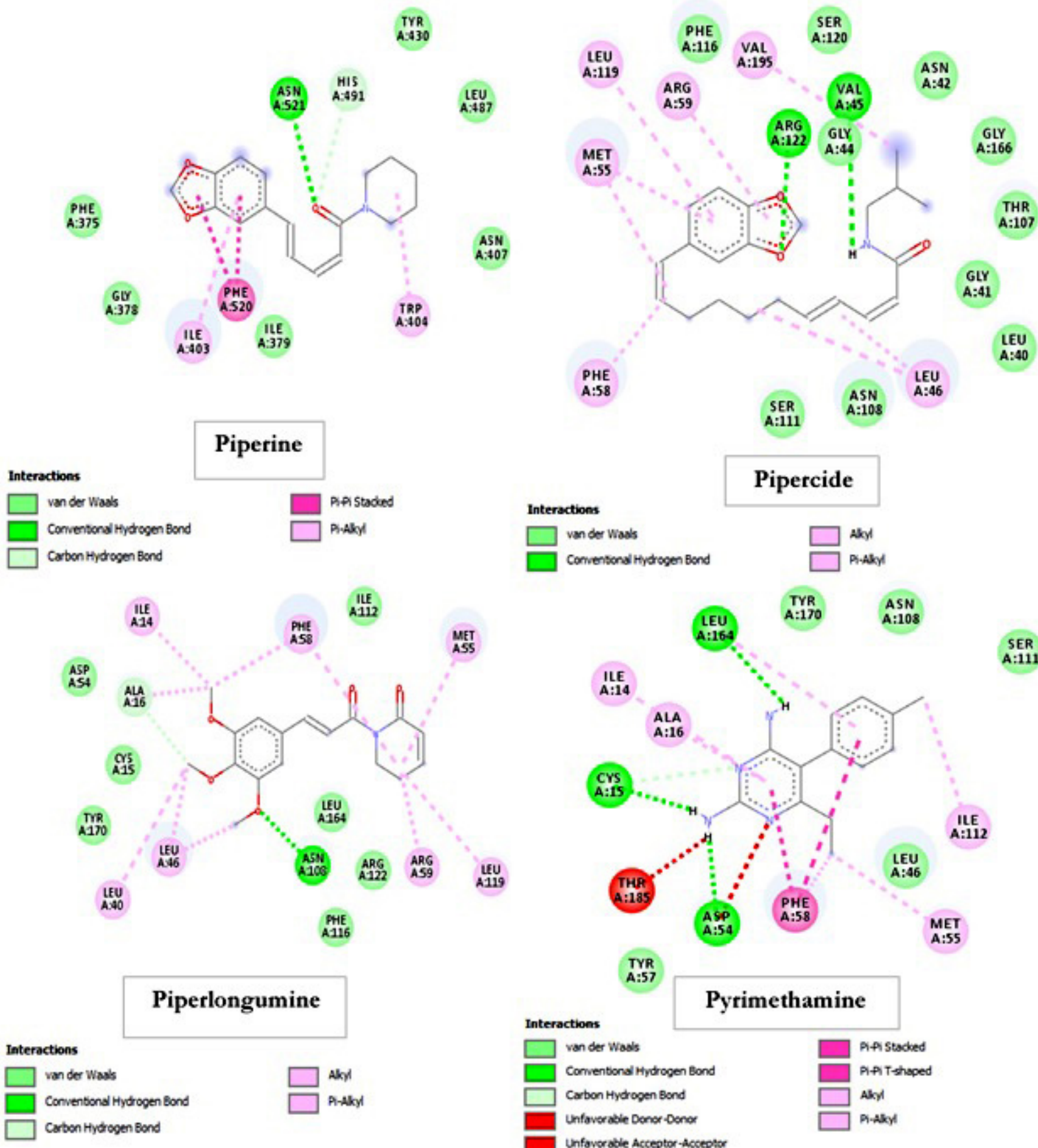

Convertonat Hydregen bend

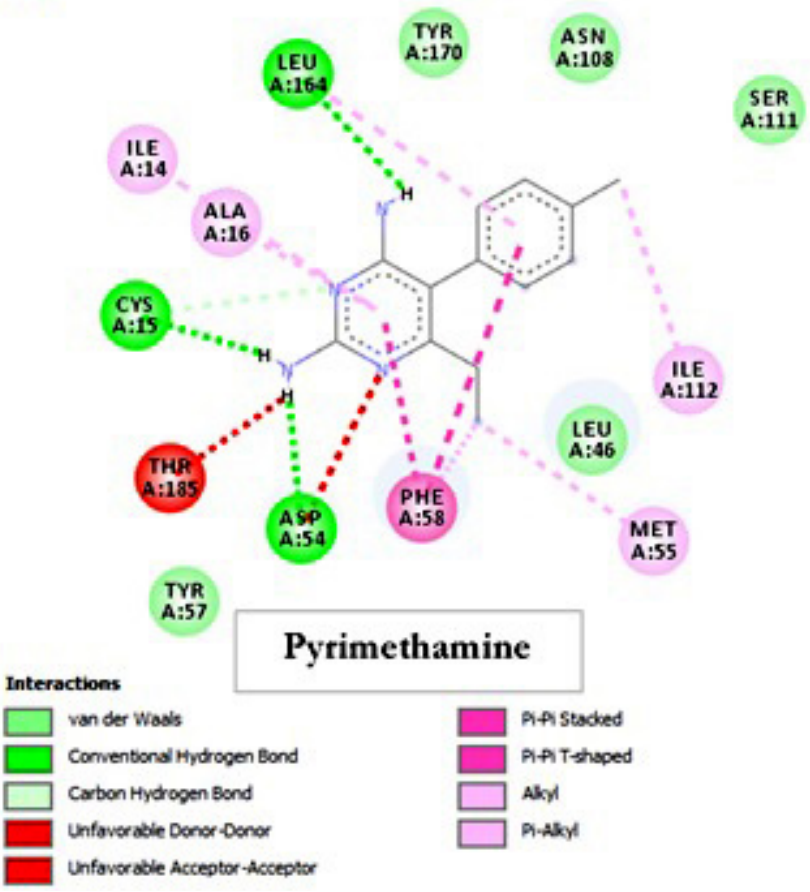

Figure 1. 2D-interaction pose of inhibitors illustrating hydrogen bonds, pi-alkyl and pi-pi stacking formed with amino acid residues at the binding pocket of pfDHFR. 
et al., 2012). Thus, residue upsets the binding of compounds around the vicinity of the conserved ARG122 (Yuthavong et al., 2012). And for inhibition to happen, interaction is required on some crucial amino acid residues, ASP54, ASN/SER108, ILEU/ LEU164, and ILE14, at the active site of the enzyme (Adane and Bharatam, 2011). The docking scores obtained from all the compounds in this present study indicate that piperine had the best affinity $(-8.3 \mathrm{kcal} / \mathrm{mol})$. Binding affinity could have been a result of the flexibility of the target area.

Pipercide interaction with pfDHODH residues revealed that the side chain of LYS 229 formed a hydrogen bond with the ligand. Also, the interaction of piperlongumine with pfDHODH showed that the side chains of ASN347, ASN458, and LYS229 formed hydrogen bonds with the ligand (Fig. 2). Furthermore,

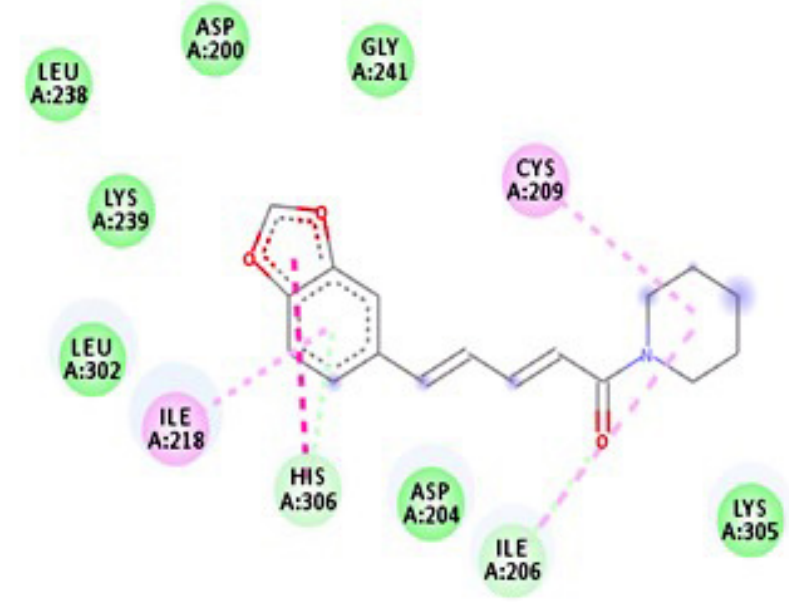

Piperine

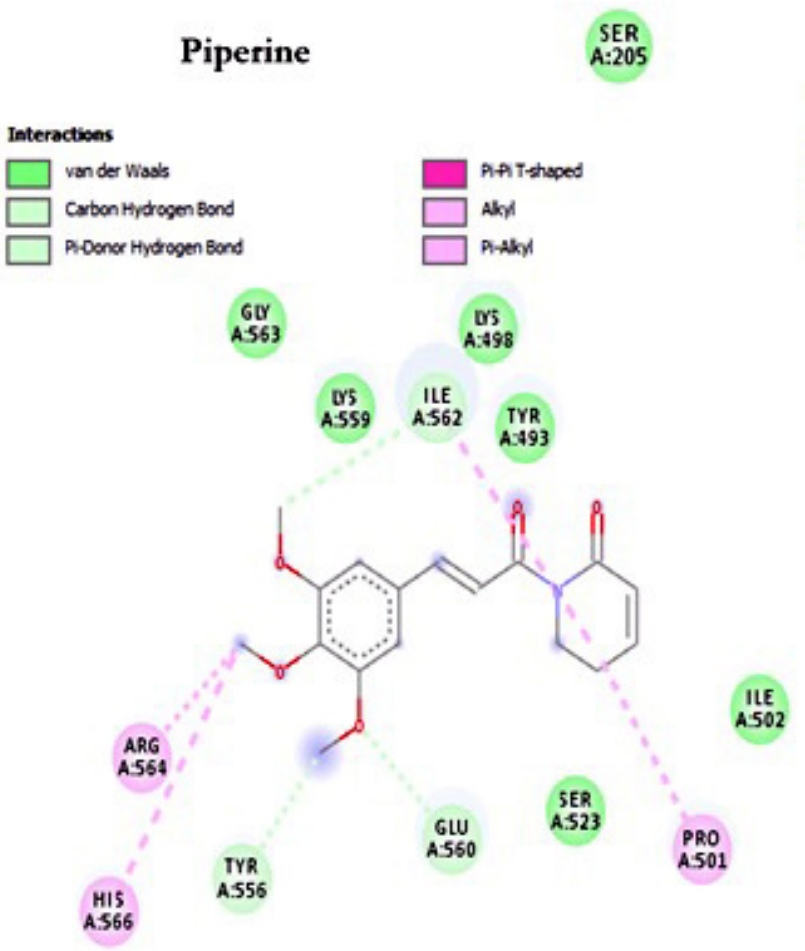

Piperlongumine

\section{Interactions}

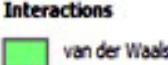

Carben Hydrogen Bond
Akph

Pi-Aky|

\section{Pipercide}
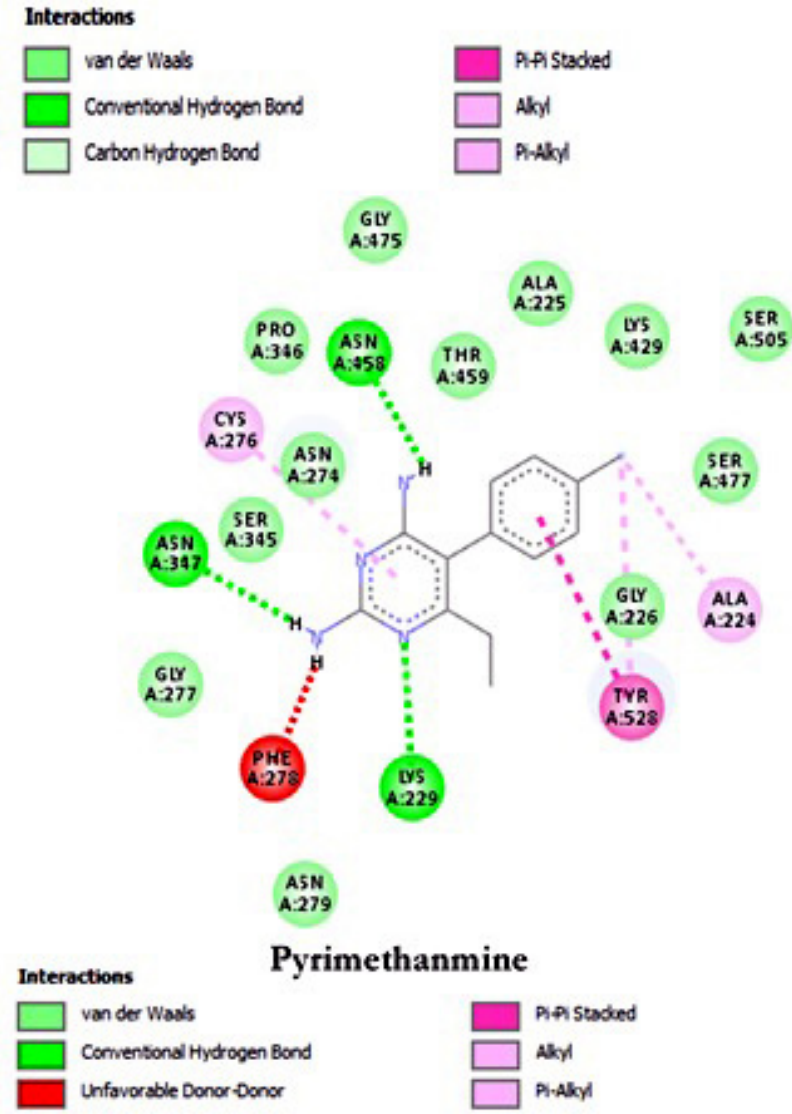

Figure 2. 2D-interaction pose of inhibitors illustrating hydrogen bonds, pi-alkyl and pi-pi stacking formed with the amino acid residues at the binding pocket of $\mathrm{pfDHODH}$ 
Table 2. Oral drug-likeness of the piperine, pipercide, piperlongumine, and pyrimethamine using Lipinski RO5 filters.

\begin{tabular}{lcccccc}
\hline Compound & $\begin{array}{c}\text { Molecular } \\
\text { weight (Dalton) }\end{array}$ & Log P & $\begin{array}{c}\text { Number of } \\
\text { HBD }\end{array}$ & $\begin{array}{c}\text { Number of } \\
\text { HBA }\end{array}$ & $\begin{array}{c}\text { Molar } \\
\text { refractivity }\end{array}$ & $\begin{array}{c}\text { Number of rotatable } \\
\text { bonds }\end{array}$ \\
\hline Piperine & 285.34 & 2.99 & 0 & 3 & 85.47 & 4 \\
Pipercide & 355.47 & 4.87 & 1 & 3 & 107.14 & 11 \\
Piperlongumine & 317.34 & 2.04 & 0 & 5 & 89.47 & 6 \\
Pyrimethamine & 248.71 & 2.29 & 2 & 2 & 71.06 & 2 \\
\hline
\end{tabular}

$\mathrm{HBD}=$ hydrogen bond donor; HBA = hydrogen bond acceptor.

Table 3. ADMET properties of piperine, pipercide, piperlongumine, and pyrimethamine predicted from admetSAR.

\begin{tabular}{lcccc}
\hline ADMET & Piperine & Pipercide & Piperlongumine & Pyrimethamine \\
\hline BBB & Yes & Yes & Yes & Yes \\
GI absorption & High & High & High & High \\
Ames toxicity & Non-toxic & Non-toxic & Non-toxic & Non-toxic \\
Carcinogenicity & Non-carcinogen & Non-carcinogen & Non-carcinogen & Non-carcinogen \\
Pgp substrate & No & No & No & No \\
CYP 2C19 inhibitor & Yes & No & No & Yes \\
CYP 2C9 inhibitor & Yes & Yes & No & No \\
CYP 1A2 inhibitor & Yes & No & No & Yes \\
CYP 2D6 inhibitor & No & Yes & No & No \\
CYP 3A4 inhibitor & No & Yes & No & Yes \\
Skin permeability $(\mathrm{cm} / \mathrm{s})$ & -5.58 & -3.76 & -6.77 & -5.91 \\
\hline ADMET $=$ absorption, distribution, metabolism, and excretion-toxicity; BBB $=$ Blood brain barrier; CYP = cytochrome; GI absorption \\
$=$ gastrointestinal absorption; P-gp $=$ permeability glycoprotein.
\end{tabular}

Figure 2 shows that pipercide and pyrimethamine form a pi-pi stacking using its phenyl ring with TYR528, respectively, which contribute to the strong inhibitor bindings (Deng et al., 2009; Hoelz et al., 2018). Besides, pyrimethamine has a better binding affinity to pfDHODH than the other compounds.

From compound analysis by Lipinski rule of five (RO5) presented in Table 2, all the compounds obeyed the RO5. It is vital to bear in mind that Lipinski's RO5 in drug discovery is a tool for determining the drug-likeness of a potential drug. And it is worthy of note that the route of drug administration influences ADMET according to Lipinski's rule (Hoelz et al., 2018; Lipinski, 2004; Ojo et al., 2020a). To examine the drug-likeness of piperine, pipercide, and piperlongumine, the ligands were evaluated using Lipinski's RO5. This was done to ascertain whether the ligands can be effective as oral drugs by evaluating them for certain biological and pharmacological properties such as hydrogen bond donor and acceptor, molecular mass, lipophilicity, and molar refractivity (Hoelz et al., 2018; Lipinski, 2004; Ojo et al., 2020b). Findings from this study indicate that all the experimental ligands passed the test for bioavailability and could be modified as antimalarial drug candidates. The study also suggests that these ligands can transverse specific biomembranes regardless of weak or strong interactions as they had a molar refractive index between 85.47 and 107.14 (Lipinski, 2004).

Adsorption, distribution, metabolism, excretion (ADME) data predicted that piperine, pipercide, and piperlongumine did not show ADME properties which could result in significant side effects in humans. Piperine, piperlongumine, and pipercide are nonsubstrates of p-gp. Piperine is an inhibitor of CYP 2C19, 2C9, and 1A2, while pipercide is an inhibitor of CYP 2C9, 3A4, and CYP 2D6, whereas piperlongumine is a noninhibitor of all the isoforms of cytochrome P450 assessed. However, piperine, pipercide, and piperlongumine could qualify as an acceptable drug that can permeate through the blood-brain barrier. Piperine, pipercide, and piperlongumine are not carcinogenic or mutagenic as shown in Table 3. All the compounds are noninhibitors of the P-glycoprotein efflux transporter and thus will not be extruded out of the cell, and the absorption and permeability of the compounds will not be impeded. ADMET performed on all bioactive compounds as well as predicted piperine, pipercide, and piperlongumine had no propensity of resulting in any side effect in humans. Besides, the candidate drugs did not show carcinogenic potential and were nontoxic in all the compounds. It is documented that potential drugs that are in agreement with the RO5 like the compounds from this study are likely to exhibit lower attrition rates in cases of clinical trials which could result in a higher possibility of getting to the open markets to be used as therapies (Rajendran et al., 2015). ADMET reduces the risk associated with late-stage attrition in drug research as a vital component of drug discovery involves testing the new drug for its effectiveness and toxicity (Meng et al., 2011).

\section{CONCLUSION}

This study reveals the binding ability of bioactive compounds from $P$. guineense as potential inhibitors of pfDHFR and pfDHODH. Piperine has a higher binding affinity with pfDHFR while pyrimethamine has a higher binding affinity with pfDHODH, interacting with amino acid residues through hydrogen bonds and $\pi-\pi$ stacking. Furthermore, studies on preclinical and clinical trials with more important wet laboratory studies are required to be conducted to validate the computationally identified molecule to be utilized as a potent antimalarial drug candidate. 


\section{AUTHOR CONTRIBUTIONS}

All authors made substantial contributions to conception and design, acquisition of data, or analysis and interpretation of data; took part in drafting the article or revising it critically for important intellectual content; agreed to submit to the current journal; gave final approval of the version to be published; and agree to be accountable for all aspects of the work. All the authors are eligible to be an author as per the international committee of medical journal editors (ICMJE) requirements/guidelines.

\section{FUNDING}

There is no funding to report.

\section{CONFLICTS OF INTEREST}

The authors report no financial or any other conflicts of interest in this work.

\section{ETHICAL APPROVALS}

This study does not involve experiments on animals or human subjects.

\section{PUBLISHER'S NOTE}

This journal remains neutral with regard to jurisdictional claims in published institutional affiliation.

\section{REFERENCES}

Adane L, Bharatam A. Computer-aided molecular design of 1H-imidazole-2,4-diamine derivatives as potential inhibitors of Plasmodium falciparum DHFR enzyme. J Mol Model, 2011; 17:657-67.

Adebayo AS, Adesina S, Gröning R. New constituents of Piper guineense fruit and leaf. Pharmazie, 2003; 58(6):423-5.

David TI, Adelakun NS, Omotuyi OI, Metibemu DS, Ekun OE, Eniafe GO, Inyang OK, Adewumi B, Enejoh OA, Owolabi RT, Oribamise EI. Molecular docking analysis of phyto-constituents from Cannabis sativa with pfDHFR. Bioinformation, 2018; 14(9):574-9.

Deng XY, Gujjar R, El Mazouni F, Kaminsky W, Malmquist NA, Goldsmith EJ, Rathod PK, Phillips MA. Structural plasticity of malaria dihydroorotate dehydrogenase allows selective binding of diverse chemical scaffolds. J Biol Chem, 2009; 284:26999-7009.

Hoelz LVB, Calil FA, Nonato MC, Pinheiro LCS, Boechat N. Plasmodium falciparum dihydroorotate dehydrogenase: a drug target against malaria. Future Med Chem, 2018; 10:1853-74.

Lipinski C. Lead- and drug-like compounds: the rule-of five revolutions. Drug Discov Today Technol, 2004; 1:337-41.

Loffler M, Fairbanks LD, Zameitat E, Marinaki AM, Simmonds HA. Pyrimidine pathways in health and disease. Trends Mol Med, 2005; 11:430-7.

Meng XY, Zhang HX, Mezei M, Cui M. Molecular docking: a powerful approach for structure-based drug discovery. Curr Comput Aided Drug Des, 2011; 7:146-57.
Ojo OA, Afon AA, Ojo AB, Ajiboye BO, Okesola MA, Aruleba RT, Adekiya TA, Oyinloye BE. Spondias mombim L. (Anacardiaceae): chemical fingerprints, inhibitory activities and molecular docking on key enzymes relevant to erectile dysfunction and Alzheimer's diseases. J Food Biochem, 2019; 43(3):e12772; doi:10.1111/jfbc.12772

Ojo OA, Aruleba RT, Adekiya TA, Sibuyi NR, Ojo AB, Ajiboye BO, Oyinloye BE, Fadaka AO. Deciphering the interaction of Puerarin with cancer macromolecules: an in silico investigation. J Biomol Struct Dyn, 2020b; 1-12. doi: 10.1080/07391102.2020.1819425

Ojo OA, Ojo AB, Taiwo OA, Oluba OM. Novel coronavirus (SARS-CoV-2) main protease: molecular docking of puerarin as a potential inhibitor, PREPRINT (Version 1) 2020a. Available via https://doi org/10.21203/rs.3.rs-37794/v1

Oyinloye BE, Adekiya TA, Aruleba T, Ojo OA, Ajiboye BO. Structure based docking studies of GLUT4 towards exploring selected phytochemicals from Somalia xanthocarpum as a therapeutic target for the treatment of cancer. Curr Drug Discov Technol, 2019; 16(4):406-16.

Oyinloye BE, Osunsanmi FO, Ajiboye BO, Ojo OA, Kappo AP. Modulatory effect of methanol extract of Piper guineense in $\mathrm{CCl}_{4}$ induced hepatotoxicity in male rats. Int J Environ Res Public Health, 2017; 14(9):955; doi:10.3390/ijerph14090955

Phillips MA, Rathod PK. Plasmodium falciparum dihydroorotate dehydrogenase: a promising target for novel anti-malarial chemotherapy. Infect Disord Drug Targets, 2010; 10:226-39.

Rajendran K, Rajaram A, Dhanarajan B, Madhiyalagan H. Protein ligand interaction using AutoDock in bio-computing. Int J Emerg Technol Innov Eng, 2015; 1:67-71.

Singh IV, Mishra S. Molecular docking analysis of pyrimethamine derivatives with Plasmodium falciparum dihydrofolate reductase. Bioinformation, 2018, 14(5):232-5.

Vyas VK, Ghate M. Recent developments in the medicinal chemistry and therapeutic potential of dihydroorotate dehydrogenase (DHODH) inhibitors. Mini Rev Med Chem, 2011; 11:1039-55.

World Health Organization. World Malaria Report. 2019 Available via http://www.who.int/malaria/publications/world-malariareport-2019/en/ (Accessed December 2019)

Yuthavong Y, Tarnchompoo B, Vilaivan T, Chitnumsub P, Kamchonwongpaisan S, Charman S, McLennan D, White K, Vivas L, Bongard E, Thongphanchang C, Taweechai S, Vanichtanankul J, Rattanajak R, Arwon U, Fantauzzi P, Yuvaniyama J, Charman W, Matthews D. Malarial dihydrofolate reductase as a paradigm for drug development against a resistance-compromised target. Proc Natl Acad Sci U S A, 2012; 109(42):16823-8

How to cite this article:

Ojo OA. Exploring the potentials of selected bioactive compounds isolated from Piper guineense Schumach. \& Thonn. leaf towards identification of novel pfDHFR and pfDHODH inhibitors as antimalaria agents. J Appl Pharm Sci, 2021; 11(04):153-158. 